\title{
O “LUGAR" DO FILHO ADOTIVO NA DINÂMICA PARENTAL: REVISÃO INTEGRATIVA DE LITERATURA
}

THE "PLACE" OF THE ADOPTED CHILD IN PARENTAL DYNAMICS: AN INTEGRATIVE REVIEW OF LITERATURE

EL “LUGAR” DEL HIJO ADOPTIVO EN LA DINÁMICA PARENTAL: UNA REVISIÓN INTEGRADORA DE LA LITERATURA

Ana Bárbara Morelli* Fabio Scorsolini-Comin** Tales Vilela Santeiro***

\section{Resumo}

O estudo objetivou apresentar uma revisão integrativa de literatura acerca do lugar reservado às crianças na dinâmica dos pretendentes à adoção. $\mathrm{O}$ espaço destinado à criança no psiquismo parental fornece indícios de como será a interação entre os membros da nova família. Critérios de busca para definição da amostra $(N=24)$ : artigos disponíveis nas bases LILACS, SciELO e PePSIC; publicados entre 2002 e 2012; e cruzamento dos unitermos "pais", "casais", "adoção", "fantasia" e "psicanálise". Os resultados apontaram quatro categorias temáticas: (a) motivaçóes e preconceitos apresentados pelos pais adotivos; (b) temores sobre o momento de revelação da adoção ao filho; (c) necessidade de preparo dos pais para a filiaçâo adotiva; e (d) presença de apoio profissional para prevenção da devolução filial. Conclui-se que os pais adotivos devem se preparar para a parentalidade, promovendo adaptaçóes ambientais, sociais e psíquicas para a chegada dos filhos. A atenção psicológica nesse processo é recomendada.

Palavras-chave: adoção; família; parentalidade; psicanálise; literatura de revisão.

* Universidade Federal do Triângulo Mineiro, Uberaba, MG, Brasil.

** Universidade Federal do Triângulo Mineiro, Uberaba, MG, Brasil.

*** Universidade Federal de Goiás, Jataí, Goiás, Brasil. 


\section{Abstract}

The study aimed to present an integrative review of literature about the place reserved for children, in the dynamics of applicants for adoption. The space for the child in the parental psyche provides clues about how will be the interaction between members of the new family. Criteria to define the sample $(N=24)$ : articles available in LILACS, SciELO and PEPSIC; published between 2002 and 2012; crossing of keywords "parent", "couples", "adoption", "fantasy" and "psychoanalysis". The results showed four thematic categories: (a) motivations and preconceptions presented by adoptive parents, (b) concerns about the timing of disclosure of the adoption to the child, (c) need to prepare parents for adoptive filiation, (d) the presence of professional support to prevent filial devolution. We conclude that the adoptive parents must prepare for parenthood, promoting environmental, social and psychic adaptations to the arrival of the children. The psychological attention in this process is recommended.

Keywords: adoption; family; parenting; psychoanalysis; review literature.

\section{RESUMEN}

El objetivo fue proporcionar una revisión integradora de la literatura sobre el lugar reservado para los niños en la dinámica de los solicitantes de adopción. El espacio para el niño en la psique de los padres proporcionará pistas sobre la interacción entre los miembros de la nueva familia. Criterios de búsqueda para definir la muestra $(N=24)$ : artículos disponibles en LILACS, SciELO y PEPSIC, publicados entre 2002-2012, y cruce de palabras "padre", "parejas", "adopción", "fantasía" y "psicoanálisis". Los resultados mostraron cuatro categorías: (a) las motivaciones y prejuicios de los padres adoptivos; (b) las preocupaciones acerca de la divulgación de adopción para el niño; (c) necesidad de prepara a los padres; (d) el apoyo profesional para la prevención del regreso de los nińos adoptados. Los padres adoptivos deben prepararse, promoviendo adaptaciones ambientales, sociales y psíquicas para la llegada de los hijos. Se recomienda la atención psicológica en este proceso.

Palabras clave: adopción; familia; paternidad; psicoanálisis; literatura de revisión. 
A construção da parentalidade é um processo contínuo, de modo que refletir sobre as motivaçôes, fantasias e medos subjacentes dos pais é fundamental para compreendê-la e favorecer intervençóes de promoção de saúde. Investigar como o lugar do bebê inscreve-se no universo simbólico parental é possível pelo discurso que os pais tecem acerca dele. Essa constituição vincula-se, também, à capacidade subjetiva dos pais de construírem uma imagem do filho, criarem sonhos e expectativas a seu respeito, atribuindo-lhes características familiares, fatores que interferem na sua constituição como ser, o que ocorre tanto nos casos de filiação biológica como adotiva (Kamers \& Baratto, 2004; Zornig, 2010).

Este estudo destaca a construção da parentalidade adotiva. A adoção é uma decisão que implica adaptação e elaboração psíquica por parte de todos os envolvidos - pais, irmãos e demais familiares (D’Amato, 2010; Wade, 2010). Teoricamente, a nova família deve suprir condiçóes para o desenvolvimento corporal, emocional e psicológico do filho adotado ocorrer de modo mais saudável (Winnicott, 1954/1997), tal como se espera de um grupo familiar baseado em vínculos biológicos. Nesse mesmo sentido, pais pretendentes à adoção devem se preparar enquanto aguardam a chegada do filho adotivo, assim como os biológicos o fazem durante a gestação, preparação esta que envolve não apenas a aquisição de informaçôes, mas também a construção da parentalidade (Hueb, 2012; Otuka, Scorsolini-Comin, \& Santos, 2013; Winnicott, 1955/1997; Zornig, 2010).

A psicanálise, em especial as contribuiçôes de D. W. Winnicott, pode contribuir para a compreensão da importância da construção do "lugar" do filho adotivo no psiquismo dos pais. Na perspectiva winnicottiana, quando o meio ambiente proporciona condiçóes adequadas para o sujeito lidar com os conflitos oriundos de tensóes instintuais, é nomeado como suficientemente bom, que auxilia na constituição do ser. Essa interação do sujeito com o ambiente se inicia antes do nascimento biológico e interfere na sua constituição física e psíquica. Nesse sentido, o existir psíquico preexiste ao físico e o ambiente se modifica para acolher a nova pessoa (Gueller \& Souza, 2008). Nessa vertente teórica, existe uma história que envolve e marca o lugar do bebê no mundo real e também há correspondências desse lugar em nível simbólico. Conhecer essa história e preparar-se para o exercício da parentalidade é fundamental para que esta ocorra de modo saudável e adaptativo, tendo em vista a assunção de uma nova família. Na parentalidade adotiva, essa preparação mostra-se importante para que a nova família possa se constituir.

Partindo dessa consideração teórica, este estudo visou investigar, de modo geral e por meio de literatura publicada em periódicos científicos, o lugar inscrito para as crianças na dinâmica parental dos pretendentes à adoção, além de abordar as vicissitudes que permeiam o processo e podem dificultá-lo. Para tanto, duas 
problemáticas foram norteadoras da revisão: (1) de que modo estudos têm investigado o lugar inscrito para as crianças na dinâmica e nas fantasias parentais dos pretendentes à adoção?; e (2) quais as motivaçōes dos pretendentes que buscam um processo de adoção?

\section{Método}

\section{Tipo de estudo}

Trata-se de uma revisão integrativa da literatura científica nacional. É uma estratégia metodológica que visa não apenas mapear a produção científica e sistematizá-la, mas justamente integrá-la a fim de permitir uma reflexão aprofundada acerca da produçáo científica a respeito de determinado tema e subsidiar novas pesquisas e práticas baseadas em evidências. Os procedimentos adotados nessa revisão seguem a proposta de Mendes, Silveira e Galvão (2008): (1) identificação do tema e da questão norteadora; (2) estabelecimento de critérios de inclusão/exclusão; (3) categorização dos estudos; (4) avaliação dos estudos; (5) interpretação dos resultados; (6) síntese do conhecimento.

\section{Bases indexadoras e descritores}

O material foi acessado por meio das bases eletrônicas e de acesso aberto LILACS, SciELO e PePSIC. Os descritores utilizados foram: "pais", "casais", "adoção", "fantasia" e "psicanálise", bem como suas variantes em inglês e suas combinações a partir do operador booleano "and".

Critérios de inclusão

(1) artigos indexados e disponíveis na íntegra; (2) nos idiomas português e inglês; (3) publicados no período de janeiro de 2002 a junho de 2012; (4) com temática pertinente aos objetivos da revisão.

\section{Critérios de exclusão}

(1) artigos que eventualmente não abordassem o tema investigado; (2) artigos que tiveram ocorrência repetida nas diferentes bases de dados; (3) livros, 
monografias, capítulos de livro, resenhas, cartas, notícias, dissertaçóes e teses; (4) artigos que abordassem tangencialmente a temática. A seleção exclusiva de artigos publicados em periódicos visou a cotejar produçóes que passam por uma avaliação por pares e segue a tendência de outros estudos de revisão (Scorsolini-Comin, 2014).

\section{Procedimentos}

A busca inicial ocorreu em junho de 2012 e a partir dela 360 estudos foram acessados. Eles correspondiam à somatória de todas as buscas realizadas com os descritores utilizados. Em momento posterior, a aplicação dos critérios de inclusão e exclusão indicou quais trabalhos eram pertinentes, o que reduziu o tamanho amostral para 58. Após uma primeira seleção realizada por meio dos resumos, os artigos selecionados foram recuperados, lidos na íntegra e submetidos a uma leitura analítica realizada de modo independente pelo segundo e pelo terceiro autor do presente estudo. As análises realizadas consensualmente de início foram aceitas automaticamente. Já as análises realizadas de maneira discordante foram discutidas caso a caso até que se chegasse a um comum acordo. Como resultado dessa fase, a amostra final foi definida $(N=24)$.

Após a aplicação do procedimento para definição do corpus de análise e do exame em profundidade do material, categorias temáticas foram construídas em função dos enfoques presentes nas publicaçōes: (a) motivações e preconceitos apresentados pelos pais adotivos; (b) temores sobre o momento de revelação da adoção ao filho; (c) necessidade de preparo dos pais para a filiaçáo adotiva; e (d) presença de apoio profissional para prevenção da devolução filial. A apresentação de resultados e da discussão seguirá essas categorias temáticas.

\section{Resultados e discussão}

O Quadro 1 apresenta, de modo sintético, a caracterização dos artigos recuperados conforme títulos, autores, periódicos divulgadores, classificação no Qualis CAPES da área de Psicologia em abril de 2013 (CAPES, 2012a, 2012b), ano de publicação e tipos de estudos. Esta última categoria refere-se ao fato de o artigo ser teórico, empírico ou de revisão de literatura e o classifica quanto à abordagem de pesquisa utilizada (qualitativa, quantitativa ou mista) e aos instrumentos empregados (entrevistas, questionários, escalas, técnicas projetivas, entre outros). 


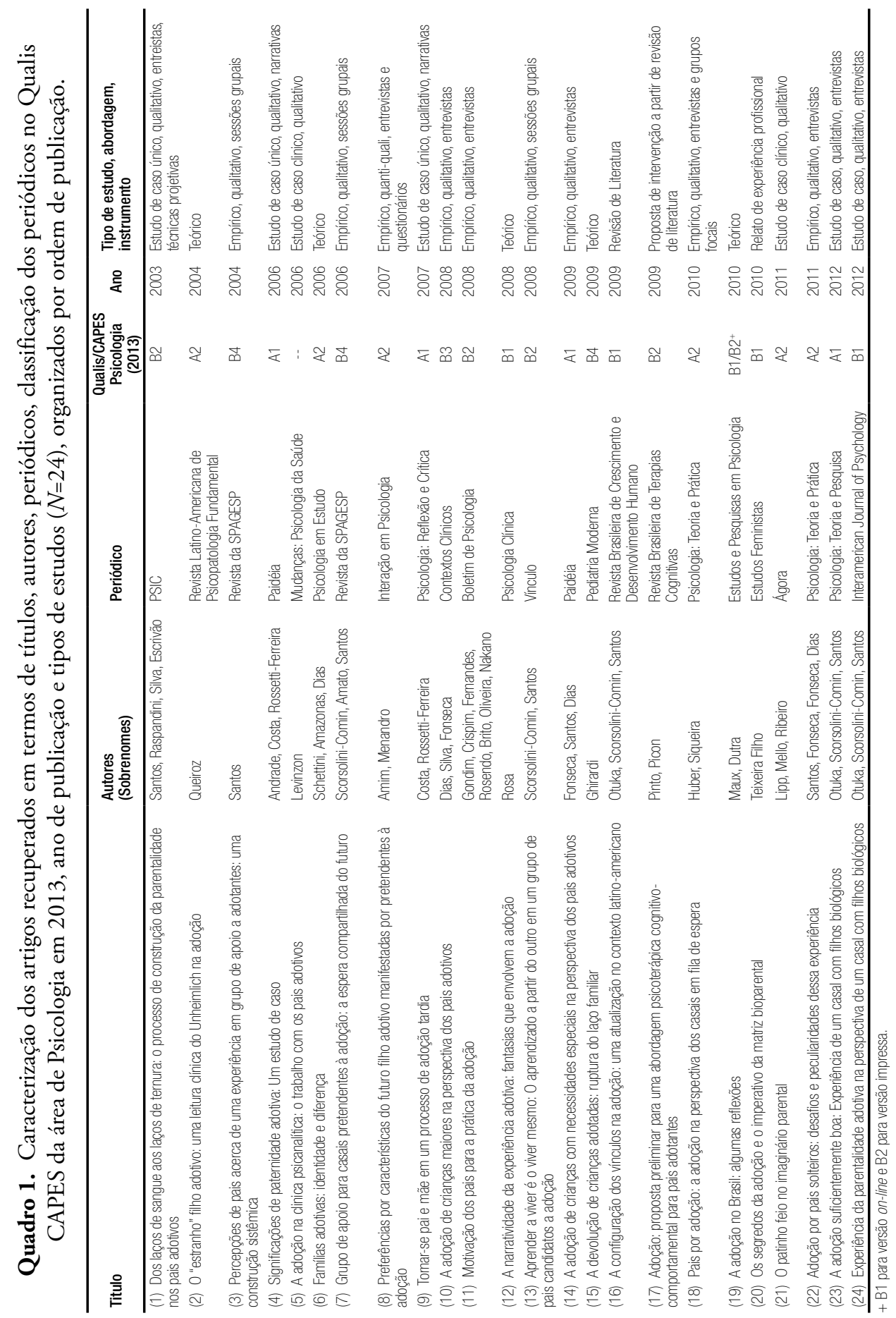




\section{Motivaçôes e preconceitos apresentados pelos pais adotivos}

As motivaçóes que levam os adultos a pleitearem a adoção de uma criança ou adolescente são diversas. Compreendê-las foi o movimento enfocado em alguns estudos recuperados. Nos cônjuges, o desejo de ter um filho será constituído de forma distinta em cada um de acordo com vários fatores, sendo importante identificar as motivaçóes individuais (Otuka, Scorsolini-Comin, \& Santos, 2009).

As motivações mais declaradas pelos pais para optarem pela adoção foram: altruísmo, desejo de ser pai/mãe e medo da solidão (Fonseca, Santos, \& Dias, 2009; Gondim et al., 2008; Levinzon, 2006; Otuka et al., 2009; Schettini, Amazonas, \& Dias, 2006). Alguns estudos apontaram, ainda, que a maioria das pessoas recorre à adoção diante da infertilidade de um dos membros do casal (Andrade, Costa, \& Rossetti-Ferreira, 2006; Gondim et al., 2008; Maux \& Dutra, 2010; Santos, Raspantini, Silva, \& Escrivão, 2003; Scorsolini-Comin, Amato, \& Santos, 2006; Scorsolini-Comin \& Santos, 2008; Schettini et al., 2006; Pinto \& Picon, 2009).

$\mathrm{Na}$ vertente psicanalítica, a impossibilidade de ter filhos de forma natural tende a causar feridas narcísicas nas pessoas, que buscam, de forma inconsciente, deixar descendentes como modo simbólico de burlar a mortalidade. A busca da adoção como saída diante da dor gerada pela impossibilidade de procriação proporciona aos pais a vivência do narcisismo, mas a presença da criança também pode significar sua limitação de náo poder gerar, fortalecendo a antinomia da relação (Levinzon, 2006). Portanto, deve-se procurar exercer o luto pelo filho biológico que não pode vir e trabalhar angústias inerentes à infertilidade para evitar possíveis dificuldades na relação com a criança ou o adolescente adotado.

A elaboração do luto envolve também a resolução do conflito entre o filho ideal e o filho real, uma vez que a experiência do luto da perda do filho imaginado favorece a aceitação do filho real em sua plenitude. Assim, com o elaborar da idealização, o casal passa a aceitar o adotivo como filho, e este, por sua vez, passa a assumi-los como pais (Ghirardi, 2009; Otuka et al., 2009; Pinto \& Picon, 2009; Rosa, 2008; Santos et al., 2003; Schettini et al., 2006). Quando se atribui à família adotiva a função de substituir e imitar a biológica, incorre-se no risco de negar a história de origem da criança e suas diferenças. É preciso assimilar as especificidades e os fatores inconscientes que movem os pais no processo de parentalidade adotiva (Schettini et al., 2006). Há de se destacar, ainda, que o luto pelo filho ideal não é exclusivo da parentalidade adotiva, também ocorre na filiação biológica.

Os pretendentes à adoção costumam fazer algumas exigências referentes à escolha do perfil de criança desejada. A preferência costuma ser por bebês saudá- 
veis, da mesma cor de pele da família (na maioria das vezes, brancas) e meninas (Weber, 2010), sendo que essas características não correspondem à realidade encontrada nas instituiçōes de acolhimento brasileiras. Fonseca et al. (2009) questionaram se essas preferências (muitas vezes exigências) indicariam que o foco da adoção ainda é a necessidade de realizar desejos dos pretendentes. Pode ser uma tentativa de imitar a família biológica e assim manter o processo da adoção como segredo frente à sociedade (Maux \& Dutra, 2010).

A preferência por bebês costuma ser justificada pela ilusão de que são mais adaptáveis, fáceis de serem "lapidados" e de que isso seria possível dando os primeiros cuidados, imitando a família biológica. Os pais "esquecem" que o filho possui uma história pessoal pregressa que não pode ser negada, ocultada ou rejeitada (Amim \& Menandro, 2007; Dias, Silva, \& Fonseca, 2008; Gondim et al., 2008; Huber \& Siqueira, 2010; Schettini et al., 2006).

Quando se discorre sobre a adoçáo tardia ou adoção da criança em idade maior, é comum a crença de que crianças maiores trazem maus hábitos, apresentam problemas de adaptaçáo, trazem o conhecimento sobre sua adoção e fortes lembranças do passado, o que lhes traria futuros problemas (Amim \& Menandro, 2007; Costa \& Rossetti-Ferreira, 2007; Dias et al., 2008; Gondim et al., 2008; Otuka et al., 2009; Santos, Fonseca, Fonseca, \& Dias, 2011). Crianças maiores, quando adotadas, tendem a discordar das regras, marcando seu direito de dizer "não" na casa. No decorrer do tempo, com o recebimento de apoio e amor, passam a reescrever sua história.

Dias et al. (2008) entrevistaram quatro pais adotivos recentes, sendo um homem e três mulheres, investigando as dificuldades encontradas na adoção. Os participantes verbalizaram dificuldades devido ao fato de as crianças terem sido abandonadas anteriormente, sentindo-se rejeitadas, além de testarem o amor dos pais. No entanto, todos os participantes relataram estar felizes com a paternidade/ maternidade, independente das vicissitudes do processo, encaradas como comuns na relação entre pais e filhos. Os pais adotivos sugerem que os pretendentes à adoçáo procurem auxílio psicológico, reflitam sobre preconceitos e frequentem grupos de apoio para terem uma preparação adequada e conduzirem a adoção de forma ideal. O estudo de Costa e Rossetti-Ferreira (2007), que abordou as motivaçóes e dificuldades da adoção de crianças maiores, relatou caso sobre o tema. As autoras destacaram as dificuldades relatadas pelo pai, que se viu contestado em suas regras diante da expressão da sexualidade de uma das meninas.

A escolha por meninas deve-se ao estereótipo herdado culturalmente que caracteriza o sexo feminino como frágil, dócil e fácil de ser educado. Observa-se o pensamento errôneo de que essas características estão inscritas no biológi- 
co quando, na verdade, remetem à dominação masculina (Amim \& Menandro, 2007; Costa \& Rossetti-Ferreira, 2007; Gondim et al., 2008). A escolha de menina também pode ser justificada pelo medo inconsciente, enraizado em vivências edípicas, do incesto entre mãe e filho, para se evitar a rivalidade entre pai e filho (Teixeira Filho, 2010). A escolha de crianças brancas ou da mesma cor de pele e traços tem o intuito de identificar a criança com a família, podendo, assim, denotar tanto o desejo de imitação da família biológica, quanto a dificuldade de elaboração do luto pela infertilidade. A alta procura de crianças brancas objetiva a identificação, visto que a maioria dos candidatos à adoção são brancos (Amim \& Menandro, 2007; Teixeira Filho, 2010).

Fonseca et al. (2009) expóem as dificuldades e motivaçóes da adoção de crianças com necessidades especiais. Para os pais que procuram adotá-las, a normalidade toma outra dimensão, ela passa a ser vista como o ritmo de desenvolvimento de cada um. De modo semelhante ao observado no caso de pretendentes a adoção de outras crianças, as motivações para a adoção dessas crianças são muitas, como: bondade, religião e maturidade para assumir a responsabilidade.

A valorização de laços consanguíneos auxilia na formação de preconceitos da filiação. Os estudos atribuem importância aos fatores biológicos e estímulos ambientais para o desenvolvimento humano, no entanto é mais cômodo justificar condutas pela genética do que refletir sobre o ambiente. Um preconceito inerente à sociedade é de que as crianças tragam consigo condutas ruins devido ao que nomeiam "sangue ruim", mostrando desconhecimento sobre genética (Maux \& Dutra, 2010).

A discussão sobre motivaçóes e preferências dos pretendentes precisa considerar que aquelas crianças disponíveis para adoção que não se adequam aos requisitos preestabelecidos por determinada família permanecem acolhidas institucionalmente (Amim \& Menandro, 2007; Andrade et al., 2006; Costa \& Rossetti-Ferreira, 2007; Dias et al., 2008; Gondim et al., 2008; Maux \& Dutra, 2010; Teixeira Filho, 2010). É imperativo que psicólogos e outros profissionais envolvidos nos processos adotivos reflitam sobre as implicaçóes dessas decisóes em suas práticas profissionais e, talvez mais especialmente, nas vidas das crianças e adolescentes acolhidos, primando sempre pelo respeito ao direito e ao bem-estar desses jovens.

\section{Temores sobre o momento de revelação da adoção ao filho}

Outro tópico que despontou da análise do material de pesquisa foi o referente às fantasias que consideram o processo de revelação da adoção como algo te- 
meroso. Nesse sentido, em uma pesquisa qualitativa realizada com quatro casais, de idades entre 31 e 50 anos, que se encontravam na lista de espera para adoção, foram evidenciadas verbalizaçóes de medos como o de que os filhos pudessem apresentar dificuldades futuras devido ao abandono em uma fase inicial da vida, de que eles queiram conhecer a família biológica e de que laços sanguíneos possam distanciá-lo da adotiva (Huber \& Siqueira, 2010).

Levinzon (2006) relatou a história de uma mãe adotiva que não conseguia revelar a adoção para a filha, já que o marido não desejava comunicar-lhe a verdade. A mãe assumia a responsabilidade pela impossibilidade do casal de ter filhos biológicos, ocultando a infertilidade do marido, e passava a nutrir sentimentos ambíguos por ele. Todas as demonstraçóes de individualidade da menina eram interpretadas como características herdadas da mãe biológica.

Otuka, Scorsolini-Comin e Santos (2012a) apresentaram um estudo de caso na vertente winnicottiana que mostra o medo envolvido na revelaçáo e como a realidade contribuiu para fortificação da fantasia de roubo da criança. O casal possuía dois filhos biológicos antes da adoção. Motivada por necessidades altruístas, a mãe acolheu um menino, o apego foi estabelecido e passou a desejá-lo como filho, entrando com o pedido de adoçáo. Os autores destacaram que o pai ouviu uma história sobre um caso de adoçáo revelada no qual o menino se "transformou", reforçando a crença irracional da força do "sangue ruim". Em outro estudo de caso, desenvolvido com um casal que já possuía filhos biológicos antes da adoção, os mesmos autores destacaram que a adoção assumiu intensa significação emocional para o casal, destacando-se a aprendizagem do "ser mãe" por meio da afiliação social como uma experiência diferente da vivência anterior de maternidade pela via biológica (Otuka, Scorsolini-Comin, \& Santos, 2012b).

Andrade et al. (2006) entrevistaram dois homens casados participantes do grupo de apoio à adoção que buscaram adotar devido à infertilidade. No primeiro caso, embora o pretendente soubesse que a revelaçẫo da adoção era importante, negava o passado da criança, pois não conseguia comunicá-la, enfrentando preconceitos da sociedade. No segundo caso, o pai não tinha medo da herança genética e acreditava que a convivência era mais importante para o desenvolvimento da personalidade. Em ambos os casos, o grupo de apoio foi aviltado como importante recurso no auxílio às novas famílias.

No início da convivência da criança com a nova família, ela passa por um processo de estranhamento, visto que não pertence ao meio, e os pais adotivos deveriam procurar modos para integrá-la. A ideia da revelaçáo da adoçáo traz à tona o receio de que, ao resgatar as origens desconhecidas da criança, o estranhamento volte. Esse resgate ainda apresenta o potencial de despertar o medo inconsciente 
do incesto, pois ele evidencia a ausência de laços consanguíneos que garantem, ao menos em tese, a interdiçáo do desejo incestuoso que se instala pelo conflito edipiano (Queiroz, 2004).

Os pais adotivos, inconscientemente, sentem que roubaram o filho de outro casal e que, a qualquer momento, estes podem reivindicar seus direitos e levar a criança, supervalorizando a filiação biológica. A fantasia do roubo está entrelaçada com os medos do abandono e da perda implicados na insegurança: quando a criança souber da verdade, ela irá necessariamente buscar os pais biológicos. Esses receios dificultam a imposiçẫo de limites aos filhos, levando à proteção exacerbada, ou resultando na dificuldade de comunicação acerca da adoção (Huber \& Siqueira, 2010; Levinzon, 2006; Otuka et al., 2009, 2012a, 2012b; Ghirardi, 2009).

Além disso, a revelação da adoção desperta fantasias que já se encontravam nos pais quando idealizavam o processo adotivo. Quando essas não são trabalhadas, a comunicação sobre a adoção perde a naturalidade e ressurgem questionamentos acerca da identidade da criança e do casal como pais, além de retomar sensações negativas relacionadas (Huber \& Siqueira, 2010; Schettini et al., 2006). Essas questóes devem ser amplamente discutidas para que os pais optem em falar sobre a adoção abertamente com a criança, pois a omissão da verdade desperta fantasias e devaneios que podem ser perturbadores para ela. O "não dito" marca a adoção como segredo e coopera com o aparecimento de sintomas. $\mathrm{O}$ mesmo ocorre quando se fala a verdade, mas se deixam lacunas sem esclarecimentos, transformando o assunto em tabu (Queiroz, 2004; Otuka et al., 2009; Rosa, 2008).

As informaçóes dolorosas a respeito da adoção podem não ter sido assimiladas pelo casal, tornando o processo traumático e prejudicial à saúde psíquica da criança. Entretanto, não é preciso esperar um momento ou idade certa, posto que a revelação deve ser um processo inserido no cotidiano da família. As crianças precisam receber o apoio de um terceiro e ouvir sobre a adoção de forma natural. Para tanto, os pais devem ser receptivos a questionamentos (Lipp, Mello, \& Ribeiro, 2011; Maux \& Dutra, 2010; Pinto \& Picon, 2009), lembrando-se sempre que a história de cada pessoa é construída continuamente. Quando o filho narra sua história, não só a relembra, como também a reconstrói, de modo que eventos iniciais não tornam sua história definitiva (Rosa, 2008).

Em contraponto à dificuldade de se tornar o processo adotivo claro, a chamada "adoçáo suficientemente boa" é aquela em que o processo permitiu mudança de papéis, negociaçóes e transformaçóes na estrutura familiar. Essa dinâmica leva, ainda, à adaptação de todos, permitindo a construção de laços fortes 
e o estabelecimento de condiçóes para a ressignificação de fantasias envolvidas (Otuka et al., 2012a). O contar a verdade sobre a adoção é, portanto, um passo a ser dado pela nova família, que assim estaria em busca de relaçóes saudáveis. $\mathrm{O}$ preparo dos pais novamente é algo que tangencia essa questão e esse tema será focado no próximo subitem.

\section{Necessidade de preparo dos pais para a filiação adotiva}

Antes de os filhos existirem, eles já ocupam um espaço no imaginário e no mundo emocional dos pais, os quais se baseiam na relação com sua família de origem (Maux \& Dutra, 2010). O desejo de inscrever o filho no seio familiar envolve fantasias que devem ser elaboradas. A gestação simbólica tem grande chance de sucesso quando é realizado o luto do filho biológico e a aceitação do filho real (Rosa, 2008; Scorsolini-Comin et al., 2006). A gestação psicológica consiste em um processo de preparaçáo que contribui para o desenvolvimento da parentalidade adotiva de forma saudável (Gondim et al., 2008; Huber \& Siqueira, 2010; Levinzon, 2006; Schettini et al., 2006; Santos et al., 2011).

Lipp et al. (2011) exemplificaram o lugar imaginário criado pelos pais para a criança: a idealizaçáo é resultado desse desejo inconsciente da paternidade e da maternidade. Relataram o caso de um menino agressivo com dificuldades de aprendizagem e de respeitar regras. Ele não tinha conhecimento de sua adoção e o segredo denotava conflitos e fantasias negativas. As queixas escolares apareciam como sintoma da estrutura familiar, denunciando os segredos que envolviam o mundo interno do filho. Todos os comportamentos reprovados pelos pais mostraram-se associados à herança genética da família biológica desconhecida, afastando o menino do papel filial ao não corresponder à idealização paterna e, por conseguinte, atribuindo-lhe o lugar de fracasso.

Pela perspectiva psicanalítica, quando o bebê nasce está circunscrito no inconsciente dos pais por meio de projeçôes. Na relação adotiva, o que é esperado e imaginado do filho adotivo interfere na constituiçáo da sua subjetividade e no seu existir no mundo (Otuka et al. 2012a; Schettini et al., 2006). Ponderaçóes como essas demonstram que o preparo dos pais, suas motivaçôes, conscientes e inconscientes, e a construção de espaço para diálogos são aspectos que se sobrepóem uns aos outros. Para a família dar conta dessa complexidade o auxílio de profissionais pode ser necessário. 


\section{Presença de apoio profissional para prevenção da devolução filial}

Costa e Rossetti-Ferreira (2007) destacaram a construção da maternidade e da paternidade adotiva, enfatizando os discursos dos pais e as significações construídas. Em um relato de caso referente à adoção de uma criança maior, enfocaram a escuta atenta às práticas discursivas em diferentes contextos sobre o assunto de interesse, dentre eles o grupo de apoio à adoção. As histórias compartilhadas podem ser vistas como experiências culturais (Costa \& Rossetti-Ferreira, 2007).

Teixeira Filho (2010) afirmou que os discursos acerca da adoção revelam como enxergá-la frente à sociedade, notando-se uma íntima relação entre discurso, poder e desejo. Motivaçóes, fantasias e medos que levam as pessoas a adotarem "à brasileira" resultam de um discurso permeado de preconceitos e supervalorização do vínculo consanguíneo. A chamada adoção pronta ou "à brasileira" ocorre quando há o encaminhamento do bebê para terceiros, sem intermediação do Poder Judiciário. Essa prática, frequente no contexto brasileiro, passou a ser considerada crime pela Lei no 12.010/09, conhecida popularmente como a "nova lei da adoçáo" (Brasil, 2009). Essa lei é considerada um avanço na área e trouxe, entre outras coisas, a obrigatoriedade de que todos os postulantes à adoção passem por uma preparação que, na maior parte dos casos, ocorre em grupos de apoio. Tal regulamentação surgiu quando os órgãos públicos identificaram a necessidade de preparo de candidatos para lidarem com o processo de adaptaçáo que envolve a efetivação da adoção (Hueb, 2012).

Outro estudo destacou a dinâmica de um casal frente à adoção e os fatores que podem resultar na devolução do filho adotado. A devolução normalmente é oriunda das dificuldades de estabelecimento de vínculo afetivo entre pais e adotado após a adoção decretada ou no período de convivência. Para a criança, a devolução é encarada como um novo abandono, reforçando seu significado de rejeição, e, para os pais, pode ser interpretada como uma resposta à fantasia inconsciente de roubo que perpretaram. O entendimento dos conflitos pelo auxílio profissional pode mudar o rumo da história (Ghirardi, 2009).

Os grupos de apoio objetivam auxiliar na compreensão dos futuros desafios, percepção e quebra de preconceitos, dissoluçáo de fantasias descabidas, além de oferecer suporte psicológico, informaçôes e esclarecimentos legais. Assim como os eventos científicos e palestras, eles visam a fortalecer e disseminar a cultura da adoção (Dias et al., 2008; Huber \& Siqueira, 2010). O apoio psicológico a pretendentes permite que as exigências em relação à criança sejam flexibilizadas, angústias sejam acolhidas, medos compartilhados e diversas dúvidas sejam devidamente esclarecidas, favorecendo que os postulantes tenham condiçóes plenas 
de decidir pela adoção e de efetivá-la de modo adequado e atento às necessidades do adotando (Gondim et al., 2008; Hueb, 2012; Schettini et al., 2006).

Alguns estudos recuperados nesta revisão são anteriores à nova lei da adoção, de modo que os grupos de apoio foram desenvolvidos pelos respectivos autores que os relataram como uma inovação ou como um recurso para os casais pretendentes à adoção. Uma exigência decorrente dessa legislação é a existência de profissionais, como psicólogos e assistentes sociais, aptos a trabalhar com a temática e disponíveis para o acompanhamento dos pretendentes à adoção.

Scorsolini-Comin e Santos (2008) analisaram os fatores terapêuticos presentes em um grupo de casais pretendentes à adoção. $\mathrm{O}$ espaço grupal possibilitou que os participantes se identificassem entre si e compartilhassem angústias e dúvidas acerca do processo adotivo e da construção da parentalidade. Em outro estudo também se percebeu que os testemunhos de pares despertaram nos integrantes do grupo sentimentos de esperança, segurança, confiança e otimismo frente às dificuldades (Scorsolini-Comin et al., 2006). Nessas experiências, a estratégia grupal mostrou-se um importante recurso de apoio psicológico aos pais, e não apenas como espaço informativo, promovendo a troca de experiências e a instilação de esperança. As estratégias grupais foram destacadas em outros estudos recuperados. Amim e Menandro (2007), por sua vez, destacaram a importância da participação dos casais no grupo de apoio à adoçẫo como forma de quebrar preconceitos e possibilitar a assunçấo de novos sentimentos.

O tempo de espera também contribuiu para as transformaçóes relatadas por Amim e Menandro (2007), pois ele varia de acordo com as características da criança desejada. Além de as conversas nesses grupos instigarem mudanças no modo como os pretendentes compreendem a adoção e gerarem transformaçóes nos casais, por meio do diálogo minimizam-se tensóes, solucionam-se conflitos e podem surgir divergências saudáveis e negociaçōes (Santos, 2004). Nesses contextos grupais, a presença de profissionais de saúde mental permanece como elemento fundamental, rumo à aquisiçẫo de processos de adoção positivos, para além das complexidades inerentes e retratadas nos estudos aqui considerados.

Os grupos de apoio podem funcionar como um espaço no qual os pais sejam convidados a construir o "lugar" do filho adotivo no psiquismo parental. A criação de um ambiente facilitador e apoiador pode contribuir para que esses pais postulantes à adoção elaborem o luto pelo filho ideal e abram caminho para a chegada do filho real. A preparação psíquica deve ser acompanhada pela ambiental, no sentido de adaptar a casa, a rotina e os demais membros para a chegada do novo membro que promoverá uma reconfiguração dessa família. Se esse meio proporcionar condiçóes adequadas para o sujeito lidar com conflitos oriundos 
de suas tensões instintuais, será considerado suficientemente bom, auxiliando na constituição do ser (Winnicott, 1955/1997).

\section{Consideraçóes finais}

A partir do percurso pela literatura científica sobre o tema da adoção e de suas repercussóes no seio familiar, conclui-se que, assim como os pais biológicos, os adotivos também devem se preparar para a parentalidade. O estudo destacou que o ambiente interfere na constituiçáo subjetiva do adotado, mesmo antes de sua chegada "concreta", o que é apoiado pelo referencial winnicottiano. A família carece de preparo para receber e acolher o novo integrante. Os pais adotivos que aguardam e anseiam pelo filho que vão adotar também devem adaptar o "espaço" físico e psíquico para sua chegada. Toda essa preparação constitui o processo de transição para a parentalidade, que não se encerra com a chegada da criança ao lar, mas que recobre todo o tempo que antecedeu esse fato - a preparaçáo dos pais e da família, participação nos cursos de postulantes à adoção - e também os primeiros meses ou anos da constituição dessa nova família. Amparados na perspectiva winnicottiana, pode-se afirmar que o ambiente constituído nessa transição deve constantemente fornecer elementos para que pais e filhos sintam-se confortáveis em seus novos papéis e possam desempenhá-los de maneira suficientemente boa, com espaço para o estabelecimento da confiança, da autonomia e da reciprocidade.

A síntese teórica propiciada pelos estudos analisados indicou que gestar simbolicamente é se preparar para a chegada do filho, imaginar, sonhar e refletir sobre o exercício parental e, principalmente, trabalhar os fantasmas que povoam o imaginário do(s) adotante(s). Julga-se indispensável refletir sobre as reais motivaçôes acerca da decisão de adotar, as crenças formuladas e as herdadas culturalmente. Faz-se necessário diluir expectativas irreais e a idealização formulada durante o processo de espera para que a adoção não resulte em fracasso e frustração desmesurados, já que esses contrapontos aos desejos humanos são inevitáveis.

Os estudos analisados fortalecem ponderaçóes sobre o papel dos grupos de apoio aos pretendentes à adoção e auxiliam no processo de preparo, o qual traz a possibilidade de reconstrução de histórias familiar, conjugal e parental. A escuta atenta a essas pessoas possibilita aos profissionais detectar no discurso o lugar destinado à criança no psiquismo do casal. A análise demonstrou que os pais que receberam ajuda psicoterapêutica anteriormente à concretização da adoçấo se sentiam mais confiantes e preparados para exercerem seus papéis maternos/paternos, o que não descartava a necessidade de atenção psicológica futura. Nesse sentido, 
destaca-se a atuação de diferentes profissionais, entre eles psicólogos e assistentes sociais, para intermediar necessidades de pais e filhos adotivos. Esses profissionais podem contribuir para a criaçáo de um ambiente facilitador, ajudando os pais na construção da parentalidade e nesse período de transição familiar.

Avaliar esses grupos de apoio, notadamente aqueles estabelecidos após a nova lei da adoção, e acompanhar pais e filhos nos primeiros anos da adoção pode oferecer subsídios a essas intervençóes, de modo que elas atendam às necessidades dessas famílias. Pela análise da literatura em destaque, sugere-se a possibilidade de oferta de ajuda não apenas aos postulantes à adoçáo, como exigido por lei, mas às famílias nessa transição para a parentalidade, de modo a oferecer recursos e suporte para a fase de adaptação. Esse apoio pode ocorrer também na modalidade grupal e com a participaçáo de diferentes profissionais, haja vista que as dificuldades encontradas não se restringem à esfera psicológica.

Alguns estudos analisados mostraram as motivaçóes dos pais adotivos, entretanto pouco se ocuparam da subjetividade e dos aspectos psicológicos que permeiam a adoção. No geral, eles enfatizavam, essencialmente de forma "implícita", como as crianças inscrevem-se na dinâmica parental, havendo, assim, escassez de trabalhos exibindo a importância do "lugar psíquico" destinado à criança para o desenvolvimento dos envolvidos e para o futuro da relaçáo familiar, como delimitado no referencial teórico que originou este estudo.

Ao final da revisão, destaca-se que a seleção desses artigos não reflete integralmente o estado da arte sobre o tema, trata-se de um recorte específico, desenhado a partir do estudo de três conjuntos de produçóes indexadas às bases SciELO, PePSIC e LILACS. A inclusão de artigos indexados em bases de dados que recuperem artigos produzidos em âmbitos estrangeiros incrementará contribuiçóes para as discussóes aqui tecidas. Tal limitaçáo deve ser levada a cabo em levantamentos futuros. A maior parte dos estudos emprega referenciais psicodinâmicos, o que já era esperado em função da questão norteadora do estudo.

Resguardadas as limitaçôes do estudo, é necessário ressaltar que os artigos analisados correspondem à produção científica divulgada em uma década e, enquanto tal, ela parece retratar parcela significativa de estudos publicados em periódicos de responsabilidade editorial brasileira e de alcance latino-americano. Além disso, esses artigos enfocam aspectos fundamentais que também vêm sendo considerados em outras realidades (por exemplo, D’Amato, 2010; Wade, 2010). Esse argumento se solidifica com ponderaçôes sobre a qualidade dessa produção. Além de ser publicada no formato de artigo e, portanto, ter sido aquilatada por pares (peer review), aferiçáo complementar da qualidade pode ser verificada: (a) pelo fato de se tratarem, no geral, de pesquisas com fundamentação empírica; e 
(b) por meio de avaliaçôes empreendidas pelo Sistema Qualis/CAPES sobre cada periódico divulgador (Quadro 1). Estas compreendem publicaçôes concentradas nos estratos acima de B2 (CAPES, 2012a, 2012b).

A respeito do item "b", é sabido que um veículo científico, para desfrutar de avaliaçóes semelhantes, obedece a critérios editoriais rigorosos que precisam ser mantidos ao longo do tempo. Ou seja, mesmo que o critério Qualis/CAPES considerado seja referente à avaliação atualizada em 2013 e nenhum artigo avaliado tenha sido publicado especificamente neste ano, os periódicos publicadores somente poderiam conseguir avaliaçáo positiva em momentos anteriores por causa de um "histórico editorial" consolidado em processos de avaliação arbitrada. Naturalmente, essas ponderações procuram ampliar a discussão acerca da qualidade amostral e não implicam em dizer que critérios editoriais estabelecidos por um sistema governamental sejam sinônimos de qualidade aplicáveis a todos os artigos analisados, mas sim que são indicadores a serem apreciados. A adoção de outros critérios, como os níveis de evidência, levaria a ponderaçôes diferentes, priorizando-se estudos considerados mais robustos e desenvolvidos em abordagens quantitativas, o que poderia se distanciar do objetivo desta revisão e das suas questôes norteadoras. Assim, as evidências dessa revisão devem ser analisadas com parcimônia.

Espera-se que as discussóes aqui demonstradas possam disparar outros estudos a fim de que o tema da adoção e de suas repercussões na dinâmica das famílias seja progressivamente debatido em face às atuais mudanças da adoção no cenário brasileiro e de seus aparatos legais. As repercussóes da nova lei da adoção devem ser acompanhadas pelos profissionais da área e problematizadas em práticas e estudos futuros.

\section{Referências}

Andrade, R. P., Costa, N. R., \& Rossetti-Ferreira, M. C. (2006). Significaçôes de paternidade adotiva: um estudo de caso. Paidéia, 16(34), 241-252.

Amim, I. D., \& Menandro, P. R. M. (2007). Preferências por características do futuro filho adotivo manifestadas por pretendentes à adoção. Interação em Psicologia, 11(2), 241-252.

Brasil (2009). Lei n. 12.010, de 3 de agosto de 2009. Dispóe sobre adoção. Recuperado em 3 abr., 2013, de <http://www.planalto.gov.br/ccivil_03/_ato2007-2010/2009/lei/112010. htm>. Brasília, DF: Autor.

Coordenação de Aperfeiçoamento de Pessoal de Nível Superior [CAPES] (2012a). Qualis periódicos. Recuperado em 3 abr., 2013, de <http://capes.gov.br/avaliacao/qualis>. Brasília, DF: Autor. 
Coordenação de Aperfeiçoamento de Pessoal de Nível Superior [CAPES] (2012b). Comunicado n.001/2012 - Área de Psicologia; Atualização do WebQualis da Área. Brasília: Ministério da Educação; Coordenação de Aperfeiçoamento de Pessoal de Nível Superior; Diretoria de Avaliação; Comissão Qualis Periódico da Psicologia. Recuperado em 3 abr., 2013, de <https://www.capes.gov.br/images/stories/download/avaliacao/Comunicado01-2013webqualis-psic.pdf>.

Costa, N. R. A., \& Rossetti-F-erreira, M. C. (2007). Tornar-se pai e mãe em um processo de adoção tardia. Psicologia: Reflexão e Crítica, 20(3), 425-434.

D’Amato, B. (2010). Adoption: perspectives and fantasy. Modern Psychoanalysis, 35(1), 53-67.

Dias, C. M. D. S. B., Silva, R. V. B., \& Fonseca, C. M. S. M. S. (2008). A adoçáo de crianças maiores na perspectiva dos pais adotivos. Contextos Clínicos, 1(1), 28-35.

Fonseca, C. M. S. M. S., Santos, C. P., \& Dias, C. M. S. B. (2009). A adoção de crianças com necessidades especiais na perspectiva dos pais adotivos. Paidéia, 19(44), 303-311.

Ghirardi, M. L. A. M. (2009). A devolução de crianças adotadas: ruptura do laço familiar. Pediatria Moderna, 45(2), 66-70.

Gondim, A. K., Crispim, C. S., Fernandes, F. H. T., Rosendo, J. C., Brito, T. M. C., Oliveira, U. B., \& Nakano, T. de C. (2008). Motivaçáo dos pais para a prática da adoção. Boletim de Psicologia, 58(129), 161-170.

Gueller, A. S., \& Souza, A. S. L. (2008). Especificidade da clínica psicanalítica com crianças: Uma diversidade de olhares. In A. S Gueller, \& A. S. L. Souza (Eds.), Psicanálise com crianças-Perspectivas teórico-clínicas (pp. 99-120). São Paulo: Casa do Psicólogo.

Huber, M. Z., \& Siqueira, A. C. (2010). Pais por adoção: A adoção na perspectiva dos casais em fila de espera. Psicologia: Teoria e Prática, 12(2), 200-216.

Hueb, M. F. D. (2012). Tecendo laços e desatando nós na trama da adoção. In S. M. Barroso, \& F. Scorsolini-Comin (Eds.), Diálogos em psicologia: práticas profissionais e produção do conhecimento (pp. 44-57). Uberaba, MG: Editora da UFTM.

Kamers, M., \& Baratto, G. (2004). O discurso parental e sua relação com a inscrição da criança no universo simbólico dos pais. Psicologia: Ciência e Profissão, 24(3), 40-47.

Levinzon, G. K. (2006). A adoção na clínica psicanalítica: O trabalho com os pais adotivos. Mudanças - Psicologia da Saúde, 14(1), 24-31.

Lipp, L. K., Mello, A. B. G., \& Ribeiro, M. M. S. M. (2011). O patinho feio no imaginário parental. Ágora, 14(2), 275-291.

Maux, A. A. B., \& Dutra, E. (2010). A adoção no Brasil: algumas reflexões. Estudos e Pesquisas em Psicologia, 10(2), 356-372.

Mendes, K. D. S., Silveira, R. C. C. P., \& Galvão, C. M. (2008). Revisão integrativa: método de pesquisa para a incorporaçáo de evidências na saúde e na enfermagem. Texto \& Contexto Enfermagem, 17(4), 758-764. 
Otuka, L. K., Scorsolini-Comin, F., \& Santos, M. A. (2009). A configuração dos vínculos na adoção: uma atualização no contexto latino-americano. Revista Brasileira de Crescimento Desenvolvimento Humano, 19(3), 475-486.

Otuka, L. K., Scorsolini-Comin, F., \& Santos, M. A. (2012a). A adoção suficientemente boa: Experiência de um casal com filhos biológicos. Psicologia: Teoria e Pesquisa, 28(1), 55-63.

Otuka, L. K., Scorsolini-Comin, F., \& Santos, M. A. (2012b). Experiência da parentalidade adotiva na perspectiva de um casal com filhos biológicos. Interamerican Journal of Psycho$\log y, 46(2), 307-316$.

Otuka, L. K., Scorsolini-Comin, F., \& Santos, M. A. (2013). Adoção tardia por casal divorciado e com filhos biológicos: novos contextos para a parentalidade. Estudos de Psicologia (Campinas), 30(1), 89-99.

Pinto, M. C. N., \& Picon, P. (2009). Adoção: proposta preliminar para uma abordagem psicoterápica cognitivo-comportamental para pais adotantes. Revista Brasileira de Terapias Cognitivas, 5(1), 3-17.

Queiroz, E. F. (2004). O "estranho" filho adotivo: uma leitura clínica do Unheimlich na adoção. Revista Latino-Americana de Psicopatologia Fundamental, 7(4), 100-111.

Rosa, D. B. (2008). A narratividade da experiência adotiva: fantasias que envolvem a adoção. Psicologia Clínica, 20(1), 97-110.

Santos, M. A. (2004). Percepçóes de pais acerca de uma experiência em grupo de apoio a adotantes: uma construção sistêmica. Revista da SPAGESP, 5(5), 29-36.

Santos, C. P., Fonseca, M. C. S. M., Fonseca, C. M. S. M. S., \& Dias, C. M. S. B. (2011). Adoção por pais solteiros: Desafios e peculiaridades dessa experiência. Psicologia: Teoria e Prática, 13(2), 89-102.

Santos, M. A., Raspantini, R. L., Silva, L. A. M., \& Escrivão, M. V. (2003). Dos laços de sangue aos laços de ternura: o processo de construção da parentalidade nos pais adotivos. Psic, 4(1), 14-21.

Schettini, S. S. M., Amazonas, M. C. L. A., \& Dias, C. M. S. B. (2006). Famílias adotivas: identidade e diferença. Psicologia em Estudo, 11(2), 285-293.

Scorsolini-Comin, F. (2014). Guia de orientação para iniciação científica. São Paulo: Atlas.

Scorsolini-Comin, F., Amato, L. M., \& Santos, M. A. (2006). Grupo de apoio para casais pretendentes à adoção: a espera compartilhada do futuro. Revista da SPAGESP, 7(2), 40-50.

Scorsolini-Comin, F., \& Santos, M. A. (2008). Aprender a viver é o viver mesmo: o aprendizado a partir do outro em um grupo de pais candidatos a adoção. Vínculo, 2(5), 101-219.

Teixeira Filho, F. S. (2010). Os segredos da adoção e o imperativo da matriz bioparental. Estudos Feministas, 18(1), 241-261.

Wade, J. (2010). The long gestation: adoption as a developmental milestone. Modern Psychoanalysis, 35(1), 24-52. 
Weber, L. N. D. (2010). O psicólogo e as práticas de adoção. In H. S. Gonçalves, \& E. P. Brandão (Eds.), Psicologia jurídica no Brasil (pp. 99-140). Rio de Janeiro: Nau.

Winnicott, D. W. (1997). Armadilhas na adoção. In R. Shepherd, J. Johns, \& H. T. Robinson (Eds.), Pensando sobre crianças (pp. 126-130). Porto Alegre: Artmed. (Trabalho original publicado em 1954)

Winnicott, D. W. (1997). A adolescência das crianças adotadas. In R. Shepherd, J. Johns, \& H. T. Robinson (Eds.), Pensando sobre crianças (pp. 131-143). Porto Alegre: Artmed. (Trabalho original publicado em 1955)

Zornig, S. M. A. (2010). Tornar-se pai, tornar-se mãe: o processo de construção da parentalidade. Tempo Psicanalitico, 42(2), 453-470.

\section{Agradecimentos}

Os autores agradecem ao CNPq pela concessão de bolsa de iniciação científica para a primeira autora.

Artigo recebido em 16 de abril de 2013

Aceito para publicaçáo em 12 de dezembro de 2013

DOI: $10.1590 / 0103-56652015000100010$ 